\title{
Perspectives on the Japanese and American Systems of Vocational Rehabilitation
}

\author{
Phillip D. Rumrill, Jr. \\ Kent State University, Center for Disability Studies, 413 White Hall, P.O. Box 5190, Kent, OH 44242-0001, USA \\ Tel.: +1 330672 0600; Fax: +1 330672 2512; E-mail: prumrill@kent.edu
}

\section{Introduction}

In today's global marketplace, the need is greater than ever before for nations around the world to understand each other's systems of education and work force development. In that endeavor, the growing worldwide effort to include people with disabilities in all aspects of society behooves rehabilitation researchers from different countries to compare and contrast approaches to Vocational Rehabilitation at policy and direct service levels. Never before have scholars in the interdisciplinary field of rehabilitation had so many opportunities to collaborate with fellow scholars from other countries, and globally-minded rehabilitationists can find countless opportunities to share their ideas at international conferences and congresses.

Work subscribers have the privilege of reading six issues per year of articles describing current research and best practices across the globe to promote positive employment outcomes, independence, and quality of life for people with disabilities. This special issue provides insights into Vocational Rehabilitation services and disability policy in Japan. Like the dynamic Japanese culture in general, services and supports for people with disabilities in Japan have changed dramatically over the past few decades. The excellent articles in this special issue bear witness to Japan's innovative and forward-thinking national approach to ensuring that people with disabilities have an accessible and inclusive place in society.
The purpose of this article is to highlight selected themes that emerge from the articles in this issue and compare and contrast current Vocational Rehabilitation trends in Japan with current Vocational Rehabilitation trends in the United States. It is a rare privilege to review the work of my friends and colleagues in Japan from my perspective as an American rehabilitation researcher and disability advocate.

\section{Reflections on the articles contained in this special issue}

The article by Arikawa, Goto, and Mineno describes two case studies of adult male workers, one with Asperger's Syndrome and one with an intellectual disability, who utilized a variety of workplace supports and other services provided by occupational therapists. The article provides excellent illustrations of the roles and functions of Japanese occupational therapists in their efforts to help people with significant disabilities seek, secure, and maintain integrated employment.

As with the American vocational rehabilitation process, occupational therapists in this study provided valuable on-the-job supports to the two Japanese workers who served as research subjects. Chief among these workplace supports were on-the-job training at the outset of employment, assessments of the workers' functional and vocational capacities, and coordination of natural supports and job accommodations in the work environment that enabled the workers to be suc- 
cessful. In the United States, occupational therapists are frequently called upon by employers, governmentoperated rehabilitation agencies, and long-term disability and workers compensation insurance carriers to conduct employability assessments, functional capacity evaluations, and job analyses to aid workers with disabilities in obtaining and maintaining competitive employment. The American vocational rehabilitation process is also greatly enhanced by the expertise in assistive technology that occupational therapists possess, especially in identifying and implementing workplace accommodations for people with disabilities.

In the article by Iwane, Yoshida, Kono, Hashimoto, and Yamamoto, the authors forecast a shifting paradigm of vocational rehabilitation services for Japanese citizens with psychiatric disabilities. They advocate an increased focus for occupational therapists and other rehabilitationists on work supports for the rehabilitant once he or she is employed, which represents a departure from the Japanese vocational rehabilitation system's historical emphasis on pre-employment work readiness. Iwane and colleagues pointed to advances in legislation and a growing commitment in Japanese society to include people with disabilities in all aspects of community living as major rationales for increasing the availability of on-the-job supports for people with psychiatric disabilities.

Indeed, a similar paradigm shift is presently occurring in the United States. Wehman (2006) described the place-and-train model of supported employment as the best model for most American workers with significant disabilities, and rehabilitation professionals in America work closely with employers to provide therapeutic and work adjustment services to workers with psychiatric disabilities at the workplace [5]. As is the case within the American system, Iwane noted that Japanese work supports for people with psychiatric disabilities work best when mental health professionals, vocational rehabilitation specialists, and occupational therapists work closely with employers and workers themselves to coordinate all necessary supports in a seamless, interdisciplinary fashion.

Matsui describes the experiences of people with disabilities working in subsidiary Japanese companies, noting that governmentally imposed quotas for hiring people with disabilities in Japan differ according to whether it is the parent company or the subsidiary company that is doing the hiring. Matsui reports that subsidiary companies are an ideal placement for Japanese workers with disabilities because the parent company is credited with the subsidiary company's hir- ing quota. This provides many employment opportunities for workers with disabilities, and it also enables large corporations to comply with Japanese hiring requirements vis a vis workers with disabilities.

Federal disability legislation in the United States has never included specific quotas that employers must meet in hiring people with disabilities, but the Rehabilitation Act of 1973 requires employers who hold government contracts to institute affirmative action policies for job applicants and employees with disabilities [3]. In 1990, the American Congress passed and President George H.W. Bush signed into law the Americans with Disabilities Act, widely known as the most comprehensive civil rights law in the world for people with disabilities. The Americans with Disabilities Act, as amended in 2008, provides a wide range of prohibitions against discriminatory treatment of people with disabilities in the workplace (and in all aspects of society, for that matter [4]).

I was struck by Matsui's report that Japanese workers with intellectual and psychiatric disabilities seem to encounter especially high levels of unfair treatment in the workplace. Studies in the United States repeatedly show that employers are less receptive to hiring people with psychiatric and intellectual disabilities than they are to hiring people with other disabling conditions [6]. McMahon [2] reported that disability type is the strongest differential indicator of workplace discrimination against people with disabilities, and he noted that people with intellectual disabilities and psychiatric disabilities have a difficult time proving to American enforcement authorities that they were subjected to unlawful treatment in the workplace.

Satio, Mineo, and Yaeda present case studies of two Japanese stroke survivors who have successfully returned to work thanks to interdisciplinary collaboration among medical, allied health, rehabilitation, and cvocational service professionals. As in the United States, the incidence of vascular diseases in Japan is on the rise, due in part to increased life expectancies, dramatic increases in the number of elderly people, and significant increases in the numbers of younger people who sustain strokes. The latter phenomenon poses unique challenges for the vocational rehabilitation process, as health care and social service professionals endeavor to help working-age people return to their jobs following strokes.

American workers are putting off retirement until older ages than they have at any other time in history. This phenomenon is encouraging on one hand because it affords American employers the opportunity 
to retain highly skilled and experienced workers even as those workers reach and advance beyond traditional retirement age. It also benefits the worker, given the well-documented therapeutic benefits of paid employment such as better overall health, increased life satisfaction, and higher-quality health insurance coverage. However, larger numbers of older workers in the labor force increase the incidence of age-related health conditions (e.g., stroke, diabetes, heart disease, arthritis) that necessitate on-the-job supports if these workers are to continue making contributions to the national economy.

Satio, Mineo, and Yaeda remind us how important it is for vocational rehabilitation services to be integrated into an interdisciplinary network of services and supports that aid people with strokes and other vascular conditions in addressing all of their health care and community living concerns. A growing number of rehabilitation professionals in the United States specialize in services for elderly individuals [7], and across the globe it seems clear that elderly workers want to continue working as long as they possibly can even as they incur age-related health conditions that require on-the-job accommodations and other workplace supports. Indeed, occupational therapists have an important role to play in addressing the vocational and independent living needs of the growing worldwide population of stroke survivors.

Watanabe describes what appears to be an innovative program for people with traumatic brain injuries (TBI) at Kanagawa Rehabilitation Center. Strong emphasis is placed on the cognitive and behavioral effects of TBI in assisting consumers in the process of re-developing their social, independent living, and vocational skills. Watanabe notes that the wide-ranging physical limitations associated with TBI conjoin with cognitive and psychological symptoms to pose tremendous obstacles to post-injury employment - even for those individuals with considerable pre-injury work experience. The same is true for Americans with TBIs. For people with TBIs and other neurological impairments in the United States, growing emphasis is placed on cognitive retraining and assistive technology as a means of restoring vocational potential [1]. American rehabilitationists are also concerned about the large numbers of military personnel who sustain TBIs and other significant disabilities in defense of our national interests in the Middle East. Toriello et al. [5] described vocational rehabilitation services within the United States Veterans Administration as overtaxed by unexpectedly high numbers of disabled veterans and limited resources to meet their needs.
Watanabe's labor force participation statistics suggest that people with TBIs in Japan experience similar difficulties re-entering the world of work following recovery from their injuries as do their American counterparts. Employment rates of under 50 percent for TBI survivors are commonly reported in both countries, and these disappointing outcomes clearly indicate the need for continued research and service delivery innovation to meet the complicated needs of individuals with TBIs. Here again, the call for interdisciplinary, holistic approaches that integrate medical, independent living, and vocational rehabilitation services is clear and compelling.

Yaeda, Kundu, and Nishimura report findings from a very interesting study of Japanese job coaches, a study that also served to validate a self-assessment for students and counselors in the field of rehabilitation. These researchers identified a number of practice settings for job coaches in Japan, namely, rehabilitation centers, welfare facilities and social work agencies, private industry, and schools. It appears that the roles and functions of job coaches in Japan are quite similar to those of job coaches in the United States, and our two countries appear to share challenges such as obtaining pre-service training and credentialing, relatively low wages, and difficulties financing job coaching services for workers who need extensive on-the-job support on an ongoing basis.

I was intrigued by the authors' description of the Job Coach Center of Tokyo, which provides training seminars for pre-service and in-service job coaches as well as providing direct job coaching services to employers and government agencies. The Center offers certificates and licenses for job coaches who complete its training program. Many programs around the United States offer training in supported employment for job coaches, but our field could benefit from an agreedupon set of unified standards upon which training and credentialing could be based.

\section{Conclusion}

Taken in aggregate, the excellent articles in this special issue provide important information about the Japanese systems of work force development and vocational rehabilitation. I thoroughly enjoyed the opportunity to review these articles, and I have concluded that, for all of the cultural differences that exist between American and Japanese societies, we are more alike than different in our desire to include people with 
disabilities in all aspects of life - and we share the perspective that work is a major factor in shaping human dignity, economic self-sufficiency, and quality of life.

\section{References}

[1] Fraser, R. T., Kraft, G. H., Ehde, D. M., \& Johnson, K. L. (2006). The MS workbook: living fully with multiple sclerosis. Oakland, CA: New Harbinger Publications, Inc.

[2] McMahon, B. (2005). Workplace discrimination against people with disabilities. Richmond, VA: Virginia Commonwealth University Rehabilitation Research and Training Center on Workplace Supports.
[3] Rubin, S., \& Roessler, R. (2005). Foundations of the vocational rehabilitation process. Austin, TX: Pro-Ed.

[4] Smart, J. (2009). Disability, society, and the individual. Austin, TX: Pro-Ed.

[5] Toriello, P., Bishop, M., \& Rumrill, P. (2012). New directions in rehabilitation counseling. Lake of the Ozarks, MO: Aspen Professional Services.

[6] Wehman, P. (2006). Life beyond the classroom: Transition strategies for youth with disabilities. Baltimore, MD: Paul H. Brookes.

[7] Wickert, K., Dresden, D., \& Rumrill, P. (2013). The sandwich generation guide to eldercare. New York: Demos Medical Publishers. 